\title{
Medical negligence: who sets the standard?
}

\author{
Kenneth McK Norrie Aberdeen University, Aberdeen
}

\section{Author's abstract}

'The law imposes the duty of care: but the standard of care is a matter of medical judgment'. So says Lord Scarman, outlining the hitherto accepted 'Bolam' standard, in his recent speech in the House of Lords decision of Sidaway $\mathrm{v}$ Bethlem Royal Hospital, reflecting earlier judicial dicta suggesting that it is for the medical profession rather than the courts to determine whether or not a medical practitioner has achieved the required standard of care (1). It is suggested here that this concept is bad in principle, and that the weight of judicial authority is against it.

Medical negligence, like all other areas of negligence, is concerned with the determination of whether the defendant came up to the standard of care he owes to the plaintiff: whether the doctor achieved the standard of care he owes to the patient. The 'duty of care' is a duty demanded by the law to achieve a certain standard, and in the 'normal' (ie non-medical) case, it has been assumed that it is for the law not only to enforce the standard but also to say what that standard is.

Cases of medical negligence on the other hand are a little different from the normal case, especially when considering the standard of care to be demanded of individual doctors. In the normal case the court is fully competent to lay down what the reasonable man should do in everyday circumstances, because judges are aware of and understand everyday circumstances. But in the case of medical negligence the court may be called upon to measure the reasonableness of medical activity about which the judge has no great level of understanding. The intricacies of medical science are not, generally speaking, within judicial knowledge, and this has led to suggestions that in a case of medical negligence it should not be left to the courts to lay down the standard to be achieved. Lord Justice Scott once made this cri de coeur when asked to judge whether a surgeon had come up to the standard demanded by the law: 'How can the ordinary judge have sufficient knowledge of surgical operations to draw such an inference (of negligence), or . . . what does he know of

\section{Key words}

Medical negligence; duty of care; medical law. the 'ordinary course of things' in a complicated abdominal operation?' (2). Perceived problems in the judge telling the surgeon that what he did he should noț have done, or that what he failed to do he should have done, may lead to the view that the judge should havew more regard to medical practice itself; that the law, in setting the standard of care it demands of a doctor? should refer to what other doctors would have done in the circumstances of the defendant doctor.

Now, such suggestions are of course perfectl这 sensible and acceptable: the law should indeed havę regard to commonly accepted medical practices i determining whether what a particular doctor did was oft was not negligent. But there have been suggestions thape this element of evidence should be regarded, not asin indication for the court to follow if it wishes, but binding determinant of what the law should demantif the way of care from the doctor. In other words, it has been suggested that a common medical practice, fron the very fact of its being accepted by a body of medicas opinion, should not be held negligent in law; and tha $\vec{E}$ a doctor charged with negligence should not suffer ap adverse verdict if it be established that what he did accorded with accepted medical practice. This view. was given expression by the Privy Council in the Canadian case of Vancouver General Hospital $\widehat{D}$ $M c D a n i e l(3)$ in which a hospital patient suffering fron diphtheria was treated by nurses who also treated smallpox patients. The plaintiff herself contracte\& smallpox, and she raised an action for negligence. The defendants claimed that the technique of common nursing was in accord with approved medical practice and Lord Alness, delivering the advice of the court: said: 'A defendant charged with negligence can cleafs his feet if he shows that he has acted in accord with general and approved practice' (4). The plaintiff los her case.

In the important Scottish case of Hunter $v$ Hanley the Lord President of the Court of Session (Lord Clyd laid down the classic test for medical negligence: 'Th true test for establishing negligence in diagnosis or treatment on the part of a doctor is whether he has beet proved to be guilty of such failure as no doctor of ordinary skill would be guilty of if acting wite ordinary care' $(6)$. The test is that of 'ordinary care Now, taking a strict view of the word 'ordinary', it maฐ 
appear that Lord Clyde was agreeing with Lord Alness, for the word 'ordinary' necessarily has regard to that which is usually or ordinarily done: 'ordinary' care becomes the same as common practice, and if the law demands that the doctor shows 'ordinary' care then the law would appear to be demanding that the doctor adopt the common practice for like circumstances: common practice becomes the exact determinant of legal acceptability, and departure therefrom is the exact determinant of negligence (7).

The leading English case setting down the standard of care is that of Bolam $v$ Friern Hospital Management Committee (8), in which McNair J said: 'The test is the standard of the ordinary skilled man exercising and professing to have that special skill' (9). Lord Scarman in Maynard $v$ West Midlands Regional Health Authority (6) accepted this test without qualification, and in Sidaway $v$ Bethlem Royal Hospital (1) he interpreted it as follows: 'A doctor is not negligent if he acts in accordance with a practice accepted at the time as proper by a responsible body of medical opinion . . . In short, the law imposes the duty of care: but the standard of care is a matter of medical judgement'.

It is respectfully suggested that the above interpretations of the test for the standard of care in Hunter and in Bolam are not accurate, and that the situation in law is that while the courts will have regard to common practice in determining the issue of negligence, they will not be bound to accept that evidence in all cases as conclusive.

The issue of common practice is one which has been considered in numerous cases of negligence not involving doctors. In the leading case of Cavanagh $v$ Ulster Weaving Co Ltd (10) the House of Lords held employers liable for not taking proper care of their employees, even although their safety precautions were shown by unchallenged evidence to be those commonly adopted in like circumstances. Though they had followed common practice, the employers were nevertheless negligent in law. The law demanded of these defendants that they go beyond common practice. There is no ground for making any distinction between this sort of case and a case in which the defendant is a skilled person such as a doctor. To say that the court does not have the requisite skill validly to pronounce on the activity in question is to ignore the fact that it is the court's duty to pronounce on whether any practice, in any walk of life, is legally acceptable. Were it otherwise, then the medical profession (or any other professional or technical body) would be able to place itself outside the law: they could set their own standards according to their own perceptions of what is acceptable. To say that the courts must have the final word as to the legal acceptability of a medical practice is not to suggest that the medical profession will abuse its position without such supervision, but simply to suggest that it must be as open to such supervision as anyone else.

There are indeed strong policy grounds for denying that the law decrees in all cases that a doctor should follow common practice in like circumstances. Every medical advance since Hippocrates has at some stage been a departure from the normal and accepted practice, and to castigate such departure as of its nature negligence is a dangerous nonsense. As Lord Clyde cogently points out in Hunter $v$ Hanley 'it would be disastrous if this were so, for all inducement to progress in medical science would then be destroyed. Even a substantial deviation from normal practice may be warranted by the particular circumstances'. It is therefore submitted that the court may be influenced but will not be bound by evidence of accepted medical practice.

Though contrary to what Lord Alness said in Vancouver General Hospital v McDaniel this approach is not inconsistent with either Hunter $v$ Hanley or Bolam v Friern Hospital. Though Lord Scarman in Sidaway interpreted the Bolam test for the 'ordinary' medical negligence case to mean that doctors may set their own standard, which the courts are bound to accept, (and then held that test inapplicable to 'informed consent' cases), he was in a minority of one with this approach. Sidaway concerned the alleged failure to disclose information of risks, and the majority held, first, that this type of negligence was subject to the identical standard in law as any other action for medical negligence; and secondly that the Bolam test, applicable to both, was not as Lord Scarman interpreted it. Rather, they held that it was for the court always to set the standard of care demanded by the law, and that this is implicit in the Bolam test itself. Lord Bridge refused to accept that the Bolam test "involves the necessity to "hand over to the medical profession the entire question of the scope of the duty of disclosure including the question whether there has been a breach of that duty" ... (E)ven in a case where, as here, no expert witness in the relevant medical field condemns the non-disclosure as being in conflict with accepted and responsible medical practice, I am of opinion that the judge might in certain circumstances come to the conclusion that disclosure of a particular risk was so obviously necessary to an informed choice on the part of the patient that no reasonably prudent medical man would fail to make it.' And Lord Templeman in the same case, though accepting that the court will be slow to conclude that a doctor following the disclosure practices of the medical profession has been negligent, emphasises in the end that it is for the court to decide, after hearing the doctor's explanation, whether the doctor has in fact been guilty of a breach of duty with regard to information'. That the court has the power to hold an almost universally accepted medical practice to be legally unacceptable should be clear from the Court of Appeal's holding in Gillick $v$ West Norfolk $\mathcal{E}$ Wisbech Area Health Authority (11) that the provision of contraceptives to girls under 16 is unlawful.

From these recent decisions it must now be clear that it is a misinterpretation of the law of professional negligence to claim that a doctor need only come up to 
the standards of his peers to be legally unchallengeable. This is not the case. Rather, a doctor, like any other person, must come up to the standard demanded by the law. That standard is one of 'reasonable care', and a doctor is not necessarily acting reasonably (in law) simply by acting as other doctors would. Doctors must be aware that it is nothing short of dangerous complacency to assume that they are safe from legal criticism if they do only as their neighbours do. A doctor is free from legal criticism only if he acts reasonably, a word which, though vague, does allow the court to take into account all the relevant facts and circumstances of the particular case. And surely this reflects medical practice in general, which is aimed to treat particular patients according to their own particular needs and circumstances rather than simply providing treatment of the sort that is normally given to that type of patient. Medical treatment is not determined by plebiscite: neither is its legal acceptability.

Kenneth $M c K$ Norrie is a Lecturer in Law at Aberdeen University, Taylor Building, Old Aberdeen, AB9 $2 U B$.

\section{References}

(1) [1985] 2 WLR 480 at p 487. See also The Times 1985 Feb 22; Bolam v Friern Hospital Management Committee [s [1957] 1 WLR 582; Sidaway v Bethlem Royal Hospital [1985] 2 WLR 480.

(2) Scott L J in Mahon v Osborne [1939] 2 KB 14 at p 23.

(3) (1934) 152 LT 56.

(4) This dictum was quoted with apparent approval in the $\overline{\bar{C}}$ House of Lords by Lord Porter in the case of Whiteford $\Phi$ $v$ Hunter [1950] WN 553.

(5) 1955 SC 200.

(6) This test has recently received the approval of the House $\overrightarrow{0}$ of Lords in Maynard $v$ West Midlands Regional Health Authority [1984] 1 WLR 634, per Lord Scarman at p 638; $\vec{\omega}$ and in Sidaway $v$ Bethlem Royal Hospital, reference (1), per Lord Bridge at p 502.

(7) This is the interpretation of Hunter suggested by RBM Howie in 'The Standard of Care in Medical Negligence' $\overrightarrow{.}$ 1983 JR 193.

(8) [1957] 1 WLR 582.

(9) The test in Bolam has been approved by the House of $\mathrm{G}$ Lords in Whitehouse v Fordan [1981] 1 All ER 267, in 음 Maynard; see reference (6) and in Sidaway; see reference (1).

(10) [1960] AC 145.

(11) [1985] 2 WLR 413. 